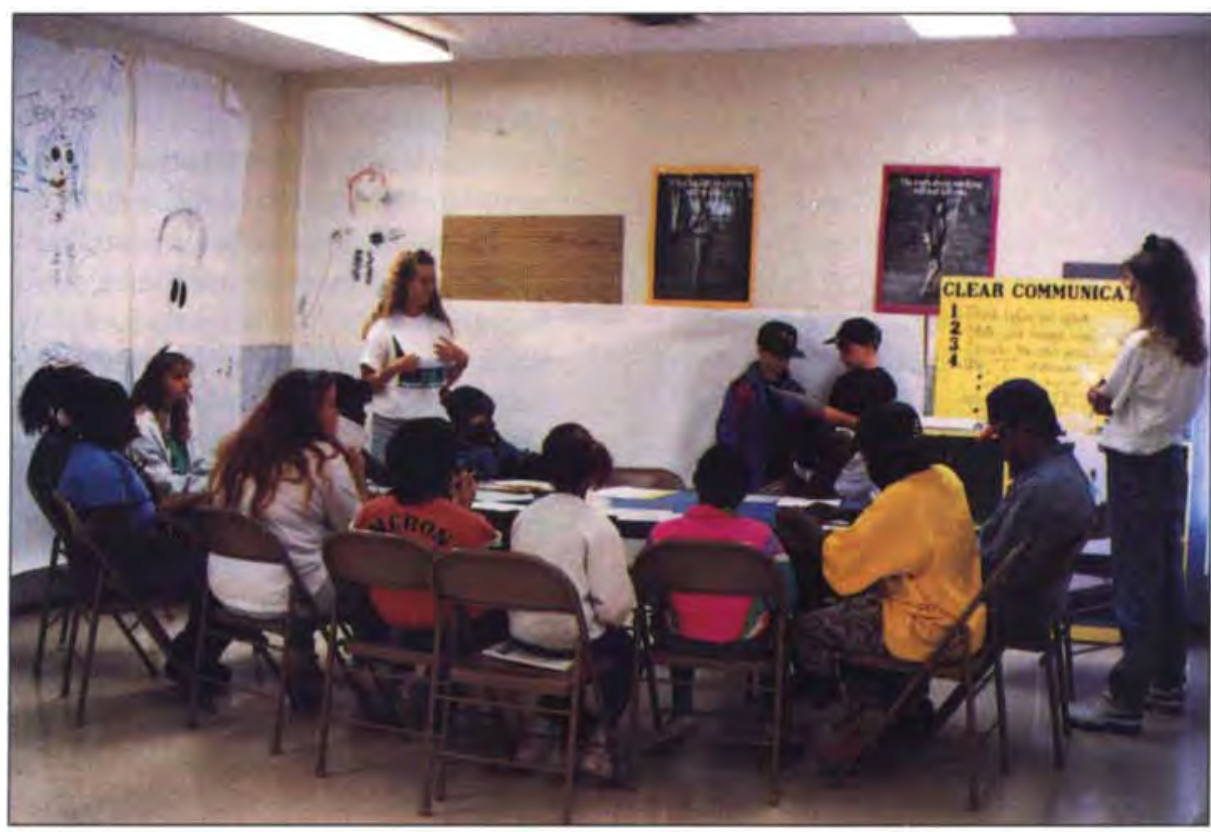

This article chronicles the research and curriculum development activities of Project 4-Health, the California 4-H program's tobacco prevention project. Studies of the social context of tobacco use, a survey of $4-\mathrm{H}$ members, a randomized field trial of the prevention curriculum, and subsequent dissemination activities are described. Major findings from each phase are presented and discussed.

Teens learn about the dangers of cigarettes and smokeless tobacco in "Project California 4-Health," which examined both personal and social factors leading teens to smoke, then delivered educational materials designed to prevent such decisions.

\title{
Project 4-Health develops program to curb youth tobacco use
}

\section{Marc}

merican society is undergoing a transformation in the way it views tobacco. Longstanding assumptions about smoking are being reexamined in areas such as health, law, public policy and advertising. Probably the most extensive public debate has focused on restrictions of public smoking, as numerous cities and counties enact tough local ordinances based on concerns about environmental tobacco smoke. Another area of controversy concerns advertising - specifically whether the Camel campaign and other cigarette ads utilizing cartoons or sports themes attract, or even were designed to target, underage youth. Another focus is the highly addictive nature of nicotine, underscored through scientific reports and debates about legal implications.

Amid these developments, prevention programs targeting tobacco have also evolved to incorporate our grow- ing understanding of adolescent substance use within the contexts of family, peer group and society. The UC Cooperative Extension (UCCE) 4-H Program and the Davis and Berkeley campuses have played leading roles in tobacco education in California through a program begun in 1985 called "Project 4-Health." In this article, we will review the major accomplishments of the project through phases of preliminary research, curriculum development and evaluation and statewide dissemination.

The original funding for Project 4-Health came from the National Cancer Institute which, in 1985, awarded a 5-year grant to UC Berkeley's School of Public Health, working in conjunction with the UCCE 4-H Program, to develop an educational program aimed at preventing the use of smokeless tobacco among youth. After preliminary investigations, it was decided the new program should deal comprehensively with both cigarettes and smokeless tobacco. Over the course of the project, we developed and evaluated a curriculum that included activity plans for six educational sessions, a Member's Book for youth, a 12-minute videotape, and a section describing a set of supplemental community activities for youth.

Dissemination of the program and further curriculum development were supported through two subsequent grants in 1991 and 1993 from the California Department of Health Services (DHS) to UC Cooperative Extension and the Davis campus. In this project, which we named "Project California 4-Health," we created a program delivery structure through which teens were recruited and trained to teach the program to 9- to 12-year-old youth. Over the course of the DHS grants we trained 719 teens, who in turn taught 
the curriculum to 5,433 youth. We also developed new curriculum materials, including a more sophisticated prevention videotape, a program delivery manual, and an adaptation of the written curriculum into Spanish.

Several specific features distinguished our project's approach: (1) it gave strong attention to smokeless tobacco as well as cigarettes; (2) it focused educational activities primarily on out-of-school community settings rather than in schools; and (3) it placed a high priority on encouraging family communications regarding tobacco.

\section{Preliminary research}

Smokeless tobacco availability. We first needed to understand the ecological context in which adolescents experimented with and used tobacco, especially smokeless tobacco (ST), about which relatively little had been published. National surveys had confirmed ST's traditional reputation as a substance most prevalent in rural communities. But by the mid-1980s, the tobacco industry had begun aggressively promoting ST to an unprecedented degree; surveys showed that its use had increased sharply among urban and suburban adolescents. To reach an informed decision about our projected target population within this changing environment, we needed to know how strongly the product's availability and promotion was linked to urban-suburban-rural geographical distinctions. Therefore we conducted an observational study of stores in the vicinity of a random sample of high schools across California to see how ST was packaged, sold, marketed, and promoted. We found that smokeless products were universally available and heavily promoted across all kinds of California communities, with only slight dropoffs in nonrural areas. These findings confirmed our belief that the curriculum would have relevance in all geographic regions of the state.

Community perceptions of smokeless tobacco. In a second study, 4- $\mathrm{H}$ advisors conducted up to 25 interviews with key informants in

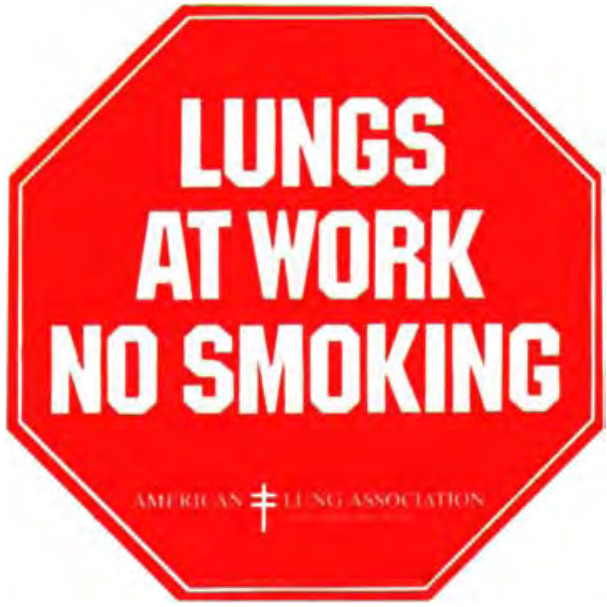

their counties, including health care professionals (such as dentists, doctors and nurses), school administrators, youth program staff, smokeless tobacco users, and kids who didn't use ST. The interviews were designed to identify terminology, determine perceptions of health problems and explore other issues associated with youngsters' ST use. We found smokeless tobacco was almost universally referred to as "chew," which therefore became our primary term of reference in the curriculum. In rural communities, our respondents reported particularly heavy spot advertising and free distribution at rodeos and car shows. We also found that there were wide variations in the concerns educators and health professionals expressed about smokeless tobacco use by youth, to a degree far greater than cigarettes. Therefore, one particularly important factor regarding the program's accep- tance in local communities would be the support of its aims by local youth leaders.

\section{Substance use patterns} among $4-\mathrm{H}$ youth. In a third study, we sought to determine the extent and nature of substance use within our specific target populations. We administered a one-time, anonymous survey in fall 1986 to California 4- $\mathrm{H}$ members, who were to be our initial audience. Altogether 2,459 youth, representing 77 clubs in 25 counties, participated in the survey. In addition to determining overall tobacco use levels, we aimed to identify factors that might be associated with tobacco use, such as age, family tobacco use, attitudes, friendship patterns, 4-H involvement, or use of alcohol and marijuana. Past developmental research, particularly Richard Jessor's problem behavior theory, asserted that all drugs - both controlled and illicit - are strongly linked for adolescents. We wanted to determine the extent to which this was true for 4-H members.

The survey results for overall use of cigarettes, ST, alcohol and marijuana, separated by age and sex, are presented in table 1. As one would expect, use of all substances was higher in the older age bracket. We found that roughly half the respondents aged 12 and older had at least experimented with cigarette smoking, and that $14.8 \%$ overall - about 1 in 7 - had smoked in the past month. As expected, a
TABLE 1. Overall substance use patterns in 1986 4-H population

\begin{tabular}{lcccc}
\hline \hline & Cigarettes & $\begin{array}{c}\text { Smokeless } \\
\text { tobacco }\end{array}$ & Alcohol & Marijuana \\
\hline $\begin{array}{l}\text { Boys, 8-11 years old }(N=441) \\
\quad \text { Never used }\end{array}$ & 78 & 77 & 66 & 96 \\
$\quad$ Used, but not in past month & 19 & 16 & 24 & 2 \\
$\quad$ Used in past month & 4 & 7 & 11 & 2 \\
Boys, 12-19 years old ( $N=521)$ & & & & \\
$\quad$ Never used & 47 & 41 & 32 & 75 \\
$\quad$ Used, but not in past month & 37 & 39 & 28 & 15 \\
$\quad$ Used in past month & 16 & 20 & 40 & 10 \\
Girls, 8-11 years old ( $N=734)$ & & & & \\
$\quad$ Never used & 86 & 95 & 85 & 99 \\
$\quad$ Used, but not in past month & 12 & 5 & 12 & 1 \\
$\quad$ Used in past month & 2 & 0 & 3 & 1 \\
Girls, 12-19 years old $(N=763)$ & & & & \\
$\quad$ Never used & 53 & 83 & 39 & 80 \\
$\quad$ Used, but not in past month & 33 & 14 & 30 & 12 \\
$\quad$ Used in past month & 14 & 3 & 31 & 8 \\
\hline $\mathrm{N}=$ number in sample & & & & \\
\hline
\end{tabular}


sharp gender difference emerged regarding smokeless tobacco: among boys, ST use was even more prevalent than cigarettes. Alcohol was by far the most widely used of the four drugs we examined, which is consistent with other adolescent populations. Among youth 12 and older, $40 \%$ of boys and $31 \%$ of girls had used alcohol within the past month. Overall, the prevalence of cigarette, alcohol and marijuana use in this $4-\mathrm{H}$ population was roughly comparable to that found in other adolescent surveys, such as the National Institute on Drug Abuse's National Household Survey and the school-based California Attorney General's Survey of Substance Use. (Precise comparisons cannot be made due to differences among surveys in age range, site of administration, and year conducted.) On the other hand, the use of smokeless tobacco appeared to be higher in our population, since most other surveys reported pastmonth usage levels of about $3 \%$ to $6 \%$ for both genders combined, whereas we found $20 \%$ among boys and $3 \%$ among girls aged 12 to 19 years old.

This survey also enabled us to determine which personal factors predicted cigarette and ST use in our $4-\mathrm{H}$ population. Highlights of the results are presented in table 2 . In computing these figures we needed to remove the influence of age, since age, being related to many activities that begin in adolescence, can create a false impression that activities are strongly related to each other in a direct way. For example, before age is statistically removed, the relationship of "Has begun dating" with cigarette use is very strong $(r=.67)$. When age is controlled, the relationship is seen to be much weaker, although still significant for girls ( $r$ between .17 and .25). Table 2 shows that the strongest predictors of tobacco use were respondent's use of alcohol and marijuana, and tobacco use by one's friends. Use by family members, especially older siblings, were also predictors, though somewhat weaker.

From this study we learned several important things that helped us with implementation of our tobacco project. First, we confirmed that smokeless to- bacco use was far more prevalent among boys than girls. This was an important consideration in our decision to develop a comprehensive program that went beyond ST alone, since we wanted our program to be relevant for our total youth audience. Second, we were able to determine that our 4$\mathrm{H}$ population is roughly similar to other adolescent populations in substance use patterns with the exception of ST, which is particularly prevalent in $4-\mathrm{H}$, probably because of the high representation of rural youth among 4$\mathrm{H}$ members.

A third important finding was that peers and older siblings seem to pose an even more potent influence on tobacco use than parents. This suggested that the dynamics of peer relationships need to be carefully addressed in the curriculum. Fourth, as table 2 makes clear, our survey confirmed past research which found that adolescent use of all drugs - tobacco, alcohol, and marijuana - is interrelated. Many researchers consider tobacco to be a gateway drug for marijuana and other illegal drugs (National Research Council, 1993). To the extent that preventing tobacco use might help to prevent or delay the use of illicit substances, tobacco prevention objectives gain an added dimension of importance beyond even the health considerations.

\section{Curriculum development, evaluation}

Most current tobacco prevention programs can be distinguished according to their general theoretical approach. "Social influence" approaches presume that tobacco use depends in large part upon the adolescent's perceptions of peer values and expectations, and that social skills can be developed to help the adolescent resist peer influences to use tobacco. Although programs based on this approach have shown some positive results, it has been criticized for not giving enough attention to the adolescent's own values, desires and decision-making capabilities. In contrast, "cognitive developmental" approaches focus on influencing the social benefits adolescents themselves might attribute to tobacco; helping them understand the psychological effects of advertising and adult models; and helping them make thoughtful decisions about tobacco use that can carry over into social situations with peers. Our approach is most consistent with the cognitive developmental model. The initial development of the curriculum entailed well over a year of
TABLE 2. Correlates of tobacco use, controlled for age

\begin{tabular}{|c|c|c|c|c|}
\hline \multirow[b]{2}{*}{ Characteristics } & \multicolumn{2}{|c|}{ Boys } & \multicolumn{2}{|c|}{ Girls } \\
\hline & Cigarettes & $\begin{array}{c}\text { Smokeless } \\
\text { tobacco }\end{array}$ & Cigarettes & $\begin{array}{c}\text { Smokeless } \\
\text { tobacco }\end{array}$ \\
\hline $\begin{array}{l}\text { Activities: } \\
\text { Football } \\
\text { Future Farmers of America } \\
\text { (Not) Music } \\
\text { (Not) Church Groups }\end{array}$ & a & $\begin{array}{l}\text { b } \\
\text { a } \\
\text { a }\end{array}$ & & a \\
\hline Started dating: & b & c & b & a \\
\hline Poor school grades: & b & a & b & a \\
\hline $\begin{array}{l}\text { Substance use in lifetime: } \\
\text { Alcohol } \\
\text { Marijuana }\end{array}$ & $\begin{array}{l}d \\
d\end{array}$ & $\begin{array}{l}d \\
c\end{array}$ & $\begin{array}{l}d \\
d\end{array}$ & $\begin{array}{l}d \\
c\end{array}$ \\
\hline $\begin{array}{l}\text { Family members who use this product: } \\
\text { Father } \\
\text { Mother } \\
\text { Older brother } \\
\text { Older sister }\end{array}$ & $\begin{array}{l}\mathrm{a} \\
\mathrm{a} \\
\mathrm{b} \\
\mathrm{a}\end{array}$ & $\begin{array}{l}\mathrm{b} \\
\mathrm{a} \\
\mathrm{b} \\
\mathrm{a}\end{array}$ & $\begin{array}{l}a \\
a \\
a \\
b\end{array}$ & $\begin{array}{l}a \\
b \\
a\end{array}$ \\
\hline Number of friends who use this product: & d & d & d & c \\
\hline Belief that one's friends approve of one's use: & d & d & d & b \\
\hline
\end{tabular}

Note: The tabled entries represent the partial correlation (controlling for respondent's age) between each correlate and the group's use of the specified type of tobacco, according to this 3-part scale: $1=$ Never used, 2 = Used but not in past month, 3 = Used in past month. The presence of "(Not)" implies that the relationship was negative in direction. $\mathrm{a}=.10 \leq \mathrm{r}<.17, \mathrm{~b}=.17 \leq \mathrm{r}<.25, \mathrm{c}=.25 \leq \mathrm{r}<.30, \mathrm{~d}=.30 \leq \mathrm{r}<.51$ 
discussion, writing, consultation, pilot testing and revision.

Each of the six educational sessions has a theme tied to a particular educational objective. For example, in Activity One, participants work in teams to produce life-size drawings of young tobacco users. Typically, those drawings depict the unattractive elements of tobacco use such as bad breath, diminished physical capacity, yellow fingers, stained clothes, and so on. The educational intent of this activity is to focus on norm group perceptions, visibly demonstrating to youth that their own peer group considers tobacco use highly unappealing. Themes for the other five activity sessions are: (a) exploring the developmental needs that tobacco is sometimes thought to serve but which can be achieved more successfully through other means (e.g., the need to demonstrate maturity); (b) understanding tobacco's effects on health; (c) analyzing the content of tobacco advertisements; (d) developing social communication skills; and, (e) reflecting on future actions regarding tobacco. In addition to these basic activities, an Action Team Guide provides ideas for participants to become involved in tobacco prevention projects in their communities.
In fall 1987, we submitted the curriculum to a formal evaluation. Using a matched-pairs experimental design, we delivered the program to youth in 37 4-H clubs, using 37 other matched clubs as a control group that did not receive the program. We pretested 10to 14 -year-old youth in these 74 clubs through a telephone survey prior to program implementation. After the program was delivered in spring 1988 , we posttested these same youth in fall 1988 (3 months after program completion), and again in spring 1990 (2 years after program completion).

Results showed that the program produced changes in a number of beliefs and attitudes related to tobacco. Among girls, the immediate posttest revealed that in comparison to the control group, girls who participated in the program (a) attributed fewer social benefits to using cigarettes and ST; (b) had more accurate perceptions of the prevalence of cigarette use and ST use; (c) believed more strongly that first use of tobacco is harmful; and (d) believed more strongly that ST use is not safer than cigarette use. No significant effects were found for girls at the 2-year followup. Little program effect was found for boys at the immediate posttest but the 2-year followup re-

TABLE 3. Paired t-tests for pre- and post-program scores during 1993 program dissemination: Items showing (A) significant change in desired direction and $(B)$ current tobacco use

\begin{tabular}{|c|c|c|c|c|c|c|c|}
\hline \multirow[b]{2}{*}{ Questionnaire item* } & \multicolumn{4}{|c|}{ Boys } & \multicolumn{3}{|c|}{ Girls } \\
\hline & Dt & Pre & Post & Sig $\neq$ & Pre & Post & Sig \\
\hline
\end{tabular}

A. Items showing significant change:

1. People who smoke a lot can quit smoking any time they want.

2. Using chew is safer than smoking cigarettes.

3. You can get hooked on chew.

4. Tobacco hurts your body the first time you use it.

5. Do you think you will smoke cigarettes when you get older?

6. Do you think you will use chew when you get older?

\begin{tabular}{ccccccc}
$\mathrm{H}$ & 3.18 & 3.57 & 0.000 & 3.08 & 3.49 & 0.000 \\
$\mathrm{H}$ & 3.84 & 4.14 & 0.000 & 4.01 & 4.32 & 0.000 \\
$\mathrm{~L}$ & 1.88 & 1.55 & 0.000 & 1.85 & 1.52 & 0.000 \\
$\mathrm{~L}$ & 2.49 & 2.19 & 0.000 & 2.17 & 2.03 & 0.002 \\
$\mathrm{~L}$ & 1.51 & 1.43 & 0.007 & 1.33 & 1.33 & $\mathrm{~ns}$ \\
$\mathrm{~L}$ & 1.32 & 1.25 & 0.011 & 1.10 & 1.11 & $\mathrm{~ns}$ \\
& & & & & & \\
& & & & & & \\
$\mathrm{~L}$ & 1.05 & 1.05 & $\mathrm{~ns}$ & 1.03 & 1.05 & $\mathrm{~ns}$ \\
$\mathrm{~L}$ & 1.05 & 1.02 & $\mathrm{~ns}$ & 1.01 & 1.01 & $\mathrm{~ns}$ \\
\hline
\end{tabular}

B. Current tobacco use:

7. In the last 30 days, how many times have you tried or smoked cigarettes, even a puft?

8. In the last $\mathbf{3 0}$ days, how many times have you used chew?

Notes:

- Items 1-4 were answered on a five-point scale, from $1=Y E S !$ to $5=N O$ I Items 5-6 were answered on a five-point scale, from $1=$ Definitely no to $5=$ Definitely yes. Items 7-8 were answered on a four-point scale, from $1=$ Never to $4=$ More than 10 times.

$\dagger \mathrm{T}=$ Desirable direction of response.

$L=$ Low (scores should decrease from pretest to posttest).

$\mathrm{H}=$ High (scores should increase from pretest to posttest).

$\ddagger$ Sig = Significance level.

$\mathrm{ns}=$ Not significant. Significance levels of .050 and less are shown.

vealed significant program effects: (a) greater opposition to trying ST and cigarettes; (b) stronger belief that the community discourages ST use; and (c) stronger belief that tobacco companies try to encourage youth to use tobacco.

From this evaluation, we learned that the program was reasonably effective in producing desired change in certain knowledge and attitude variables related to tobacco. From our process evaluation, we also learned a substantial amount about delivering our program. In particular, there was a wide range in the fidelity with which our volunteers followed the curriculum's lesson plans. We examined differences across program sites in room set-up, youth audience size, age distribution within a club, teacher characteristics, and other potentially important program implementation characteristics. From this information, we were able to strengthen our recommendations for teacher preparation and program delivery. We also observed the level of involvement of parents at each club site, and found that parent participation did not seem to have a negative effect on youth participation and attention. If anything, it may have been slightly beneficial.

\section{Program dissemination}

Under the DHS dissemination grants that began in 1991, we worked in 19 counties to deliver the program on a large scale. County $4-\mathrm{H}$ youth advisors and locally based program assistants supervised implementation by recruiting youth participants and teen teachers and scheduling sessions at local sites. Project staff based at UC Davis traveled to program counties to train volunteer teens. During this phase, due to limited resources and DHS priorities, our evaluation activities were less extensive than they had been during the randomized field trial. Using pre- and postprogram questionnaires, we assessed participants' knowledge, attitudes and values both before and after the program. This pretest-posttest design, without a control group, can reflect whether changes occurred over the course of the program but it does not permit definitive conclusions regarding whether 
the program was the cause of those changes. Table 3 presents scores for the questionnaire items on which program participants demonstrated statistically significant changes consistent with the program's educational goals. The strongest observed effects concerned knowledge of addiction and the health hazards of smokeless tobacco. In addition, there was a significant downward trend among boys in their expectations of using cigarettes and smokeless tobacco.

\section{Conclusions}

Our project's experience sheds light on several critical issues in tobacco prevention programming. First, the use of peers to deliver the program can be very effective educationally but requires careful management, and, in fact, adds considerably to program staff workload in comparison to delivering the program themselves. Extra staff time was needed to monitor, coach, counsel and, occasionally, transport high school students to elementary schools where the training occurred. There were large variations in the skill with which our teens took on their teaching tasks and we also experienced considerable attrition among teachers.

One way we addressed these challenges was to group teens into teams of at least three for each class. They were then able to provide mutual support and complement each other's strengths. In general our program confirmed the views of other researchers who believe effective peer leadership can add immeasurably to the relevance of the educational experience. Furthermore, the teen teachers themselves constitute a critical target group for educational intervention, and come away with an even richer educational experience than the children they teach. Followup interviews found that many teen teachers remained active in prevention-related activities among their peers after the program ended. Therefore, we strongly recommend using teens, but only if program time and resources permit.

A second issue to note is the differential effects for males and females, which is partly attributable to preexisting group differences. For ex- ample, table 3 shows that from pretest to posttest, boys displayed a significant drop in intentions to use both cigarettes and chew, while girls displayed no change in intentions for either substance. Nevertheless it would be incorrect to conclude the program simply did not work for girls; further inspection shows that girls had lower intentions to use each substance to begin with, and in fact the postprogram intentions of boys, though lowered significantly, still did not reach the levels for girls ( 1.43 boys vs. 1.33 girls for cigarettes and 1.25 boys vs. 1.11 girls for chew).

Table 3 also illustrates in dramatic fashion why it is often difficult for prevention programs to produce documentable changes in young audiences' actual behavior. Items 7 and 8 both involve tobacco use during the past 30 days. On a four-point scale where " 1 " represents the response "Never," the average preprogram scores ranged from 1.03 to 1.05 . In other words, actual usage was close to nonexistent even before the program started. Thus, it is not feasible to expect the program to produce a further reduction. However, this should not be taken to mean that these ages are too early to deliver prevention education. On the contrary, this is a critical period in which youth are rapidly developing knowledge structures, attitudes, values and expectations that will determine later tobacco-related behaviors. In evaluating early prevention programs, researchers pay careful attention to these precursor variables rather than to actual use.

A final issue of importance concerns the structural integrity of the educational program. Now that the curriculum has been widely disseminated we find many educators use pieces of it (such as certain activities or the videotape alone) rather than using the entire program. This is usually done to accommodate time restrictions in a busy school or program schedule. It is not possible, nor, perhaps, is it desirable to control this process once curricula become widely circulated, but since the curriculum was conceived and evaluated as a unit, one must question how effective the curriculum pieces are when presented alone. Answers to this question will vary by site, and locally based evaluations are critically important to ensure that program activities remain effective.

In conclusion, we wish to emphasize that prevention education programs should constitute only one part of a community's comprehensive prevention strategy. Educational experiences must be combined with supportive family interactions, prudent public policy decisions, consistent media messages, and

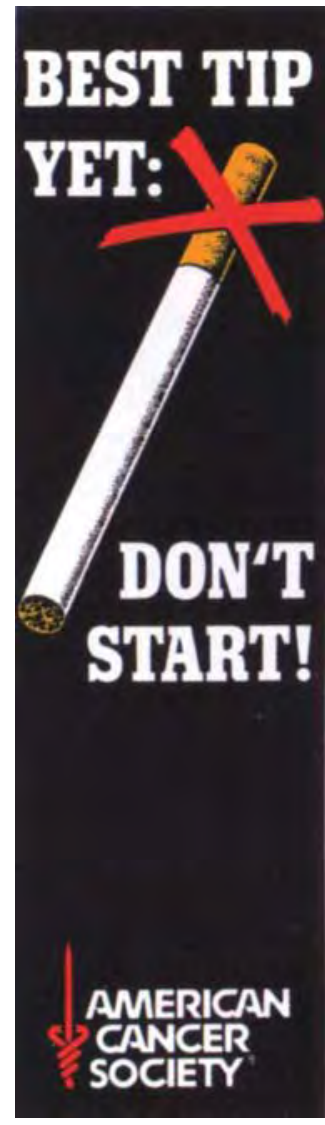
nurturance of other aspects of children's lives. These are the avenues through which young people learn to value their own health and act responsibly to preserve it.

M.T. Braverman is 4- $H$ Youth Development Specialist and Director of the Center for Youth Development in the Department of Applied Behavioral Sciences, UC Davis; J.M. Moskowitz is Associate Director, Center for Family and Community Health, School of Public Health, UC Berkeley; C.N. D'Onofrio is Associate Professor, School of Public Health, UC Berkeley; and $V$. Foster is a consultant with HealthWorks Associates, Davis, California.

\section{Further reading:}

National Cancer Institute (1991). Strategies to control tobacco use in the United States: A blueprint for public health action in the 1990s. Washington, DC: NIH Publication No. 92-3316.

National Research Council (1993). Drug abuse: What do we know? Washington, DC: National Academy Press.

Pierce, JP, et al. (1993). Tobacco use in California 1992: A focus on preventing uptake in adolescents. Sacramento: California Dept. of Health Services. 